\title{
Prostate Cancer cN0 TNM Finding v7
}

National Cancer Institute

\section{Source}

National Cancer Institute. Prostate Cancer cNO TNM Finding v7. NCI Thesaurus. Code C89224.

Prostate cancer with no regional lymph node metastasis. (from AJCC 7th Ed.) 